\title{
Inhibición dual de la neprilisina y del receptor de la angiotensina (ARNI): una alternativa en los pacientes con falla cardiaca ${ }^{\text {th }}$
}

\author{
Beatriz Wills ${ }^{a}$, Leidy P. Prada ${ }^{a}$, Alejandra Rincón ${ }^{b}$ y Andrés F. Buitrago ${ }^{c, *}$ \\ a Departamento de Medicina Interna, Fundación Santa Fe de Bogotá, Bogotá, Colombia \\ b Universidad de Los Andes, Bogotá, Colombia \\ ' Departamento de Cardiología y Epidemiología, Fundación Santa Fe de Bogotá, Bogotá, Colombia
}

Recibido el 25 de noviembre de 2014; aceptado el 2 de agosto de 2015

Disponible en Internet el 9 de octubre de 2015

\section{PALABRAS CLAVE \\ Falla cardiaca; \\ Péptidos \\ natriuréticos; \\ Antagonistas de los \\ receptores de \\ angiotensina II}

\section{KEYWORDS}

Cardiac failure; natriuretic peptides; angiotensin I receptor antagonists

\begin{abstract}
Resumen La falla cardiaca (FC) es la causa más común de admisión hospitalaria en adultos en el mundo. Además, de su importante prevalencia la FC tiene un alta tasa de mortalidad, se estima que aproximadamente el $50 \%$ de los pacientes con FC mueren a los 5 años posterior al egreso hospitalario. Esto ha motivado el desarrollo de nuevas terapias seguras y efectivas para el manejo de esta entidad. El LCZ696 es un inhibidor dual de la neprilisina y del receptor de angiotensina II que demostró en estudios de fase III disminuir el desenlace primario de muerte cardiovascular y hospitalización por empeoramiento de la FC y muerte global. Probablemente el LCZ696 se convertirá en la piedra angular del manejo en pacientes con FC con fracción de eyección deprimida.

(C) 2015 Sociedad Colombiana de Cardiología y Cirugía Cardiovascular. Publicado por Elsevier España, S.L.U. Este es un artículo Open Access bajo la licencia CC BY-NC-ND (http:// creativecommons.org/licenses/by-nc-nd/4.0/).
\end{abstract}

Dual angiotensin receptor and neprilysin inhibition (ARNI): an alternative for patients with cardiac failure

Abstract Cardiac failure (CF) is the most common cause of hospital admission in adults all over the world. In addition to its important prevalence, CF presents a high mortality rate. It is estimated that approximately $59 \%$ of patients with CF die within 5 years after the admission. This has been the motivation for the development of new, safe and effective therapies aimed at the management of this disease. LCZ696 is an angiotensin ॥ receptor-neprilysin inhibitor; phase

\footnotetext{
is Angiotensin receptor-neprilysin inhibitor.

* Autor para correspondencia.

Correo electrónico: abuitrag@uniandes.edu.co (A.F. Buitrago).
} 
III studies have shown it decreases the primary outcome of cardiovascular death and admission due to worsening of the CF and global death. LCZ696 could probably become the cornerstone of the management of patients with CF with depressed ejection fraction.

(c) 2015 Sociedad Colombiana de Cardiología y Cirugía Cardiovascular. Published by Elsevier España, S.L.U. This is an open access article under the CC BY-NC-ND license (http:// creativecommons.org/licenses/by-nc-nd/4.0/).

\section{Introducción}

Los inhibidores de la enzima convertidora de la angiotensina (IECAs) han sido por cerca de 25 años, la piedra angular del tratamiento de la FC con fracción de eyección disminuida. Hay un interés creciente en la actualidad dirigido a la neprilisina, una endopeptidasa neutra que degrada algunos péptidos endógenos vasoactivos, como los péptidos natriuréticos ( $\mathrm{PN})$, la bradiquinina y la adrenomedulina. La inhibición de la neprilisina aumenta los niveles de estas sustancias, contrabalanceando la sobreestimulación hormonal que produce una remodelación mal adaptativa en pacientes con FC.

Estudios experimentales han demostrado que la inhibición conjunta del sistema renina angiotensina aldosterona (SRAA) y de la neprilisina tiene efectos superiores a cada uno por separado. El LCZ696 (inhibidor de la neprilisina y el valsartan) fue desarrollado para disminuir el riesgo del angioedema. El PARADIGM ${ }^{1}$, es un estudio clínico controlado que probablemente convertirá al LCZ696 en la piedra angular del tratamiento médico de la FC crónica con fracción de eyección deprimida.

\section{Endopeptidasa neutra (EPN): la neprilisina}

La neprilisina, EPN, es una metaloproteinasa integral de membrana tipo 2 dependiente del zinc que hidroliza los péptidos en el residuo hidrofóbico amino-terminal. Tiene un dominio citoplásmico corto, una hélice única transmembrana y un dominio extracelular con un átomo de zinc en el sitio activo. La EPN es ubicua, se encuentra en: el riñón, el cerebro, el pulmón, las células endoteliales, el músculo liso vascular, los cardiomiocitos, los fibroblastos, los adipocitos y los neutrófilos. Los niveles más altos se encuentran en el túbulo renal proximal ${ }^{2}$.

La neprilisina es esencial para el catabolismo de los péptidos endógenos vasoactivos, además, de los PN, como la bradiquinina y la adrenomodulina. La inactivación de la neprilisina resulta en el aumento de los niveles de estas sustancias que limitan la sobreactivación neurohumoral, la retención del sodio y el remodelamiento maladaptativo (fig. 1$)^{2}$.

\section{Péptidos endógenos vasoactivos}

\section{Péptidos natriuréticos (PN)}

Los PN son una familia de hormonas vasoactivas en forma de anillo que comparten secuencias moleculares homólogas. Se han descrito cuatro tipos de PN, denominados de la A a la D.
Estos péptidos están codificados por genes distintos, tienen distribución tisular y regulaciones específicas ${ }^{3}$.

El péptido natriurético atrial (ANP), se produce principalmente en las aurículas cardiacas. Múltiples hormonas y neurotransmisores como: la endotelina, la vasopresina y las catecolaminas estimulan directamente su secreción. El estímulo principal para su producción es el aumento de la tensión de la pared auricular secundario al aumento del volumen intravascular ${ }^{4}$.

Por su parte, el péptido natriurético cerebral (BNP) se extrajó originalmente del cerebro porcino. También está presenté en el cerebro humano, su concentración es sustancialmente superior en los ventrículos cardiacos. El pro-BNP contiene 108 aminoácidos y de su procesamiento resulta un fragmento glicosilado maduro de 32 aminoácidos y un fragmento aminoterminal ${ }^{5}$.

Se han identificado dos moléculas del péptido natriurético $C$ (CNP) in vivo, de 22 y de 53 aminoácidos de tamaño. Las concentraciones plasmáticas del CNP son bajas, no obstante, el péptido de 22 aminoácidos es más potente comparado con el CNP de mayor tamaño. El CNP predomina en el sistema nervioso central, en la adenohipófisis, el riñón y las células endoteliales. Los efectos fisiológicos del CNP son distintos a los de ANP y BNP. Por un lado, el CNP no es una hormona circulante, ésta actúa principalmente a nivel autocrino y paracrino. Sus efectos natriuréticos son menores, sin embargo, tiene un rol importante en la vasodilatación e inhibición de la proliferación celular vascular ${ }^{6}$.

El cuarto miembro de esta familia es el péptido natriurético D (DNP) está compuesto por 38 aminoácidos. También tiene efectos cardiorrenales y al parecer tiene más resistencia a la degradación por el sistema de las endopeptidasas neutrales (EPN) ${ }^{2}$.

Los PN actúan a través de la interacción con receptores de alta afinidad en la superficie de las células blanco. Se han descrito tres receptores: A, B y C. La cascada de señalización de los receptores $A$ y $B$ depende de la activación del guanil monofosofato cíclico (GMPc). Los receptores $A$ y $B$ comparten aproximadamente $40 \%$ de homología estructural del dominio de la unión extracelular, por esto el receptor tipo A puede reconocer como ligando tanto al ANP (con mayor afinidad) como al BNP. El receptor tipo A es el más abundante en los grandes vasos, mientras que el receptor tipo $B$ predomina en el cerebro. Ambos se encuentran en los riñones y en las glándulas adrenales ${ }^{7}$.

La porción extracelular del receptor está conectada con la fracción intracelular a través de un único segmento ubicado en la membrana plasmática. La fracción intracelular contiene el dominio kinasa-like, seguido por el dominio catalítico guanil ciclasa (GC). La unión de los $P N$ a sus receptores activa la enzima guanil ciclasa que, a su vez 


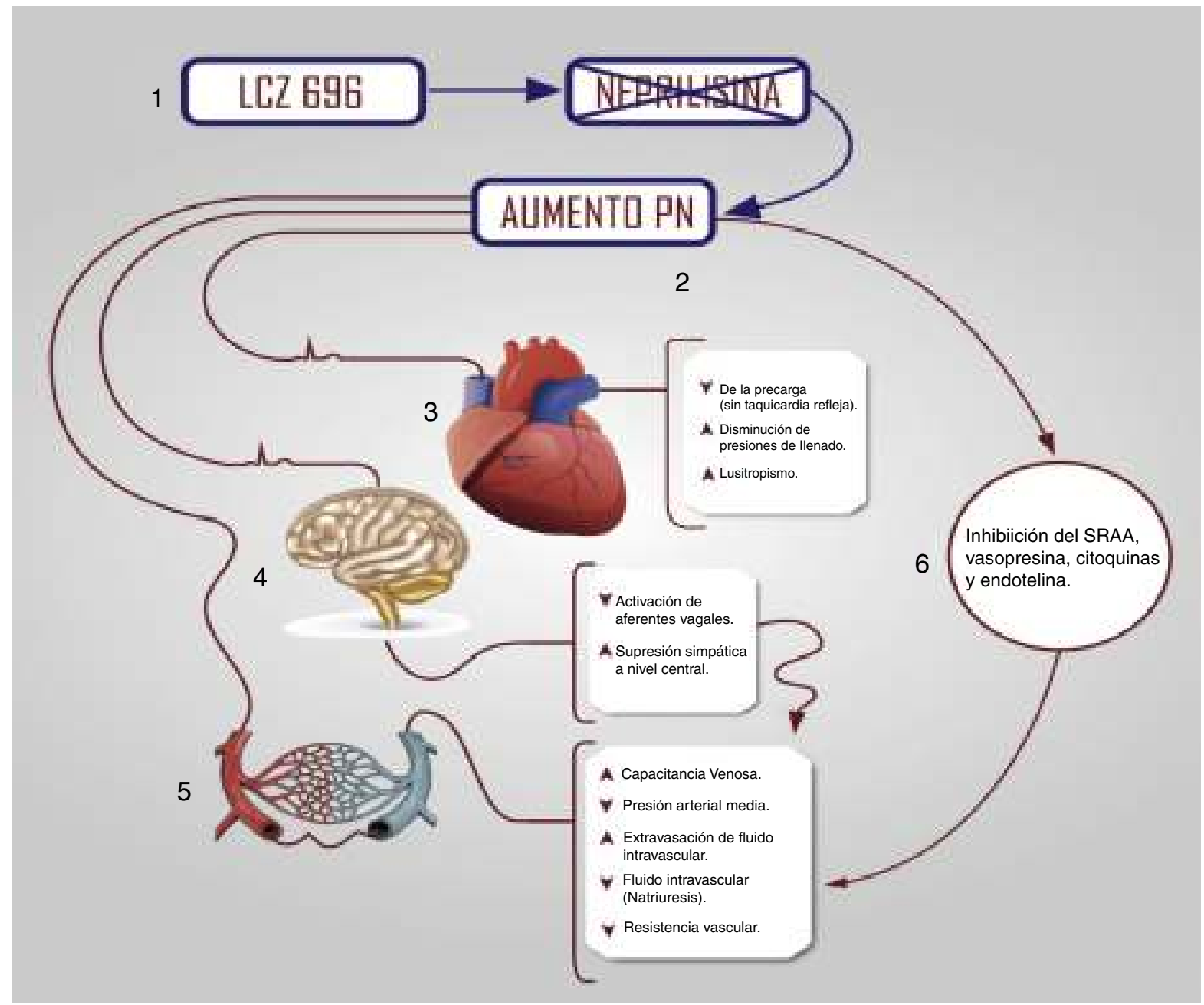

Figura 1 Efectos biológicos del LCZ696.

1. El LCZ696 inhibe la endopeptidasa neprilisina.

2. Se produce entonces un aumento en los niveles de los PN, que a su vez van a tener varios efectos cardiovasculares protectores.

3. Cardiovascular: i) Disminución de la precarga, ii) Disminución de las presiones de llenado y iii) Aumento en el lusitropismo.

4. A nivel del sistema nervioso central se produce: i) Disminución de la activación de los aferentes vagales y ii) supresión simpática a nivel central que tienen como efecto neto una disminución de la presión arterial media.

5. En las arterias y venas aparecerá: i) Aumento en la capacitancia venosa, ii) Disminución de la presión arterial media, iii) Extravasación de fluido intravascular, consecuencia de la natriuresis producida y iv) Disminución de la resistencia vascular.

6. La disminución de la resistencia vascular, la disminución en el remodelamiento mal-adapativo ocurre por el efecto inhibitorio del SRAA, la vasopresina, las citoquinas y la endotelina.

PN = Péptidos Natriuréticos, SRAA = Sistema Renina Angiotensina Aldosterona.

eleva la concentración de las intracelulares del GMPc. La inactivación de los PN ocurre principalmente a través de la EPN que escinde la estructura anular de los $\mathrm{PN}^{7}$.

\section{Efectos biológicos del sistema péptido natriurético}

\section{Acciones cardiovasculares}

Los PN tienen una amplia gama de efectos biológicos potentes en el sistema cardiovascular (fig. 1). Los efectos cardiorrenales protectores están mediados a través del GMPc. Por un lado, los PN ocasionan disminución de la precarga a través de la extravasación del fluido intravascular. Además, los PN promueven la natriuresis ocasionando reducción del volumen extravascular. El ANP y el BNP también disminuyen la resistencia vascular e inhiben el SRAA, la vasopresina, las citoquinas y la endotelina. Estos efectos son particularmente significativos cuando la fracción de eyección del ventrículo izquierdo (FEVI) está disminuida ${ }^{8}$.

Una de las propiedades más importantes del ANP y del BNP es la disminución de la precarga cardiaca sin producir taquicardia refleja. Esto probablemente se debe a la disminución en el umbral de activación de los aferentes vagales y a la supresión simpática a nivel central. Este efecto asegura que haya una disminución sostenida en la presión arterial media $^{8}$.

Otra propiedad de los PN que también llama la atención es el lusitropismo, la dilatación coronaria, los efectos 
antimitogénicos y antiinflamatorios del miocardio que potencialmente pueden reducir o incluso prevenir la remodelación cardiaca. Recientemente, se ha planteado que los PN también tienen un efecto benéfico en la tolerancia a la glucosa, en la hipertensión arterial y en el síndrome metabólico?.

En conjunto, estos efectos cardiovasculares que incluyen: la disminución de la resistencia vascular periférica, la contracción de volumen, la vasodilatación sistémica, la disminución de las presiones de llenado y el aumento en la capacitancia venosa aseguran un aumento del desempeño del miocardio ${ }^{10}$.

\section{Acciones renales}

Además, de los efectos vasculares, los PN también tienen efectos directos en la hemodinamia y la función renal. Al producir vasodilatación selectiva en las arteriolas aferentes renales, los PN aumentan la presión de los capilares glomerulares, aumentando así la filtración glomerular ${ }^{11}$. Estudios recientes han sugerido que los PN, además, tienen efectos directos en el manejo del agua y el sodio mediante la inhibición de la reabsorción de este último en las nefronas proximales y distales ${ }^{8}$. También, se ha demostrado que el aumento en la concentración de los PN en el plasma resulta en una reducción de la secreción de la aldosterona y larenina debido al aumento en la perfusión renal $^{12}$.

Si bien se ha sugerido que el ANP y el BNP tienen efectos hemodinámicos potentes, adicionalmente, existe una estimulación más eficaz dada por la urodilatina, un $\mathrm{PN}$ renal resistente a la inactivación de las endopeptidasas, lo que le confiere una ventaja como agente terapéutico ${ }^{12}$.

\section{La adrenomodulina}

La adrenomodulina (ADM), es un péptido de 52 amino anillos, que al igual que los PN, también tiene estructura anular. Esta hormona a su vez tiene efectos fisiológicos importantes como: la natriuresis, la vasodilatación, la hipotensión, la inhibición de la aldosterona e inotropismo temporal. Estas respuestas son mediadas a través del AMPc, el ON y las prostaglandinas renales. La ADM es ubicua, ejerce su función de forma autocrina y paracrina ${ }^{13}$.

Al inhibir la neprilisina, las concentraciones plasmáticas de ADM aumentan produciendo mejoría de los síntomas propios de la FC. Además, de los efectos hemodinámicos, la ADM también tiene efectos antiapoptóticos, antihipertróficos, antifibróticos, antioxidantes y anti-angiogénicos que retardan la progresión de la $\mathrm{FC}^{14}$.

Recientemente, hay un interés en la ADM como marcador de la enfermedad. Se ha encontrado que la ADM está elevada en pacientes con falla renal crónica, hipertensión y FC. Incluso los niveles de esta hormona vasoactiva se relacionan no solo con la presencia de FC, sino también con la severidad. A diferencia del BNP, la ADM tiene adicionalmente un poder predictor excelente para mortalidad a corto plazo $^{14,15}$.

\section{La bradiquinina (BK)}

La bradiquinina (BK), es una de los miembros protagonistas del sistema kalikreina-kinina (KKS), una vía enzimática compleja con diversos roles en la homeostasis cardiovascular y renal. La BK es estimulada por distintas injurias tisulares y condiciones proinflamatorias, ejerce sus efectos a través de la activación de dos receptores: B1R y B2R. Se ha demostrado que la activación del BR2 produce vasodilatación, lusitropismo y protección de las células endoteliales del estrés oxidativo a través de la liberación del óxido nítrico y de la prostaciclina PGI2 ${ }^{16,17}$.

Se ha planteado que por medio de estos efectos la BK retarda el envejecimiento precoz de los cardiomiocitos y con esto la progresión de la FC. El bloqueo de la degradación de la $\mathrm{BK}$ es en parte responsable de la eficacia de los IECAs en la FC, sin embargo, la acumulación excesiva de la BK conduce a angioedema por aumento en la permeabilidad vascular $^{18,19}$.

Otras sustancias que también se degradan a través del sistema de EPN incluyen la sustancia P, la angiotensina I, la gastrina, la beta amiloide y los péptidos opiodes. Estos efectos sistémicos explican porque la inhibición de EPN se debe acompañar de la inhibición de otros compuestos vasoactivos $^{2}$.

\section{Sistema renina-angiotensina-aldosterona (SRAA)}

Para entender la fisiopatología de la FC es imprescindible mencionar el papel fundamental del eje RAA, un sistema hormonal que regula el volumen intravascular, la presión arterial y la reparación tisular vía mecanismos inflamatorios y proliferativos. La estimulación crónica de este sistema genera: la vasoconstricción, la proliferación del músculo liso vascular, la disfunción endotelial, la inflamación, la fibrosis y la trombosis ${ }^{20}$.

La cascada del SRAA se inicia cuando las células del aparato yuxtaglomerular secretan renina en respuesta a la hipoperfusión renal, la entrega disminuida de sodio y/o activación simpática. La renina plasmática se convierte a nivel hepático en angiotensinógeno para inactivar la angiotensina ı. La enzima convertidora de angiotensina (ECA), cataliza la conversión de la angiotensina । para generar la angiotensina II, posteriormente, la angiotensina II estimula la secreción de la aldosterona en la corteza adrenal y de la arginina vasopresina en la hipófisis posterior. La aldosterona también es regulada por medio de vías independientes de la angiotensina II y está involucrada en la homeostasis de sodio y potasio $^{21-24}$.

Los péptidos involucrados en este sistema modulan la estructura del sistema cardiovascular y renal. Una de las características de la FC es la sobreactivación crónica y mal adaptativa del SRAA. Las consecuencias a largo plazo incluyen: la vasoconstricción exagerada, la disminución del gasto cardiaco, la hipertensión arterial, el aumento de la sobrecarga, la reducción de la diuresis y de la natriuresis, y la fibrosis patológica e hipertrofia en los tejidos cardiovasculares. A partir de esta explicación se deriva la importancia del bloqueo del SRAA como uno de los pilares en el tratamiento de la FC. Precisamente por este motivo, se creó el medicamento con acción dual: la inhibición del SRAA y la potenciación del sistema contrarregulatorio de los $\mathrm{PN}^{25}$. 


\section{Efectos de la inhibición de la neprilisina}

La neprilisina, también es conocida como EPN, encefalinasa o endopeptidasa EC24.11, tiene como función biológica principal la hidrólisis de los péptidos natriuréticos. La inhibición de la neprilisina aumenta los niveles circulantes de PN y agua, y además, optimiza la secreción del sodio. Adicionalmente, los niveles de endotelina-1 se reducen con la inhibición de la neprilisina al bloquear la generación de su péptido precursor ${ }^{26}$.

Dado que existen muchos sustratos para la EPN, no solo los PN, tanto la adrenomedulina como la bradiquinina que tienen acciones vasoactivas y diuréticas/natriuréticas; la inhibición de la EPN ha sido estudiada por su potencial de convertirse en una modalidad terapéutica tanto para la hipertensión como para la $\mathrm{FC}^{25,26}$.

Uno de los primeros inhibidores de la neprilisina desarrollados para el uso clínico fue el candoxatril. En humanos este medicamento causó un incremento dosis-dependiente de ANP plasmático, natriuresis y de GMP. No obstante, simultáneamente aumentó los niveles de angiotensina ॥ no acompañado de elevación de la aldosterona, probablemente por el ascenso concomitante de los demás PN los cuales suprimen la aldosterona ${ }^{27,28}$.

Los efectos del candoxatril sobre el control de la presión arterial en pacientes hipertensos no fueron significativos. Con dosis superiores, no se lograron mayores efectos sobre la presión arterial pero sí se aumentó significativamente los niveles de ANP. En los pacientes hipertensos, este inhibidor de la neprilisina produjo aumento de las moléculas vasopresoras y vasodilatadoras, dando como resultado una reducción no significativa en la presión arterial ${ }^{25,29}$. En el contexto de la FC, el candoxatril no logró mostrar reducción en la resistencia vascular sistémica y pulmonar en este grupo de pacientes, por lo que no se continuaron estudios clínicos posteriores ${ }^{27,28}$.

\section{Efectos de la inhibición dual del SRAA y de la neprilisina}

Dado que los efectos esperados sobre la presión arterial, al igual que los efectos en la FC, no fueron los esperados con la inhibición selectiva de la neprilisina, se desarrollaron compuestos con bloqueo simultáneo de la neprilisina y el SRAA. Estas moléculas se conocen por sus siglas en inglés como ARNI (Angiotensin Receptor-Neprilysin Inhibitor).

El omapatrilat fue el primer inhibidor dual, inhibe tanto la neprilisina como la ECA. Este medicamento fue más potente que el candoxatril en la reducción de la presión arterial y en la mejoría de los parámetros hemodinámicos en los pacientes con la FC. A pesar de esto no logró ser mejor que el enalapril en los desenlaces clínicos y se observó una mayor frecuencia de angioedema severo secundario a la acumulación de bradiquinina ${ }^{30,31}$.

Es por esto que se desarrolló una molécula que combina un inhibidor de la neprilisina, el sacubitril y el valsartán. Esta molécula se conoce como el LCZ696, la cual es la primera en su categoría y la única en la etapa más avanzada de desarrollo. El LCZ696 está disponible oralmente y proporciona un bloqueo con una relación 1:1 del receptor de la angiotensina 1 por medio del valsartán y de la neprilisina a través de una prodroga AHU-377 la cual se metaboliza dentro de una hora a su metabolito activo LBQ657 ${ }^{32,33}$.

Inicialmente, en modelos experimentales el LCZ696 aumentó los niveles plasmáticos de GMPc, la concentración y la actividad de la renina y de la angiotensina I. En estudios más recientes se encontró que generaba efectos potentes antihipertróficos y antifibróticos en las células cardiacas, efectos superiores a aquellos logrados con los antagonistas del receptor de la angiotensina $\|$ y los inhibidores de la neprilisina por separado ${ }^{26}$.

Estudios recientes han demostrado que la FC --contrario a lo que se pensaba anteriormente- es un estado caracterizado por depleción de los PN. Si bien los niveles plasmáticos elevados en los ensayos de inmunoquímica disponibles comercialmente en la actualidad están relacionados con el pronóstico y la exacerbación de la FC, los expertos han demostrado que en realidad los niveles biológicamente activos de los $\mathrm{PN}$ protectores están disminuidos en los pacientes con la FC, la hipertensión y la obesidad. Se ha planteado que la FC impide la maduración y procesamiento de los $\mathrm{PN}^{27}$.

\section{Evidencia clínica}

Como se mencionó anteriormente, los IECAs han sido por cerca de 25 años, la piedra angular del tratamiento de la FC con fracción de eyección disminuida (el enalapril disminuye el riesgo relativo de muerte en un $16 \%$ ). Los bloqueadores del receptor de angiotensina no tienen efectos tan claros en la mortalidad y están relegados a los pacientes que no toleran los IECAs ${ }^{34,35}$.

La inhibición conjunta del SRAA y la neprilisina tiene efectos que son superiores a cada uno por separado en estudios experimentales. Además, la asociación de un inhibidor de la neprilisina con los IECAs se ha asociado con angioedema importante. El LCZ696 (inhibidor del neprilisina: sacubitril (AHU377) más el valsartan), fue creado para disminuir el riesgo de angioedema puesto que el LCZ696 solo inhibe una de las enzimas encargadas de la degradación de la bradiquinina responsable de la aparición de angioedema ${ }^{20}$.

El PARADIGM ${ }^{1}$, es un estudio clínico controlado con enalapril, en pacientes con FC crónica, fracción de eyección menor a 40\%, clase funcional II, III o IV y tratamiento médico estándar. La dosis del enalapril se tituló hasta $10 \mathrm{mg}$ cada 12 horas (dosis promedio $18.9 \mathrm{mg}$ al día) y el LCZ696 a $200 \mathrm{mg}$ cada 12 horas. El uso de betabloqueadores y antagonistas del receptor de mineralocorticoides fue alrededor de $93 \mathrm{y}$ $54 \%$ respectivamente en los dos grupos.

El LCZ696 disminuyó el desenlace primario de muerte cardiovascular u hospitalización por empeoramiento de la FC en $20 \%(p<0.001)$ y muerte por todas las causas en $16 \%$ ( $p<0.001$ (tabla 1, fig. 2). Además, el LCZ696 se asoció con disminución significativa del riesgo de hipercalemia severa $(K>6.0 \mathrm{mg} / \mathrm{dl})$, elevación de la creatinina $\mathrm{y}$ tos. Los episodios de hipotensión arterial fueron significativamente más frecuentes con el LCZ696, pero éstos no llevaron a un aumento significativo en la descontinuación del tratamiento comparado con el enalapril $(0.9 \%$ vs. $0.7 \%$, respectivamente). La tasa de angioedema fue estadísticamente similar ${ }^{1}$.

Por el momento el LCZ696 no cuenta con aprobaciones por EMA, FDA o INVIMA. 
Tabla 1 Desenlaces primarios y secundarios del estudio PARADIGM HF

\begin{tabular}{|c|c|c|c|c|}
\hline \multicolumn{5}{|c|}{ Resultados Primarios y secundarios } \\
\hline Resultados & LCZ696 (N = 4186) & Enalapril $(\mathrm{N}=4212)$ & $\begin{array}{l}\text { Cociente de riesgo o } \\
\text { diferencia }(95 \% \mathrm{Cl})\end{array}$ & Valores de $\mathrm{P}$ \\
\hline \multicolumn{5}{|c|}{ Resultados Compuestos primarios-No. (\%) } \\
\hline $\begin{array}{l}\text { Muerte por casusas } \\
\text { cardiovasculares o primera } \\
\text { hospitalización por deterioro de } \\
\text { la falla cardiaca }\end{array}$ & $914(21.8)$ & $1117(26.5)$ & $0.80(0.73-0.87)$ & $<0.001$ \\
\hline $\begin{array}{l}\text { Muerte por causas } \\
\text { cardiovasculares }\end{array}$ & $558(13.3)$ & $693(16.5)$ & $0.80(0.71-0.89)$ & $<0.001$ \\
\hline $\begin{array}{l}\text { Primera hospitalización por } \\
\text { deterioro de la falla cardiaca }\end{array}$ & $537(12.8)$ & $658(15.6)$ & $0.79(0.71-0.89)$ & $<0.001$ \\
\hline \multicolumn{5}{|l|}{ Resultados Secundarios-No. (\%) } \\
\hline Muerte por cualquier causa & $711(17.0)$ & $835(19.8)$ & $0.84(0.76-0.93)$ & $<0.001$ \\
\hline $\begin{array}{l}\text { Cambio en el resumen clínico } \\
\text { del puntaje del } \mathrm{KCCQ}^{\dagger} \text { en } 8 \text { mo }\end{array}$ & $-2.99+-0.36$ & $-4.63+-0.36$ & $1.64(0.63-2.65)$ & 0,001 \\
\hline $\begin{array}{l}\text { Nueva aparición de fibrilación } \\
\text { auricular }\end{array}$ & $84(3.1)$ & $83(3.1)$ & $0.97(0.72-1.31)$ & 0,83 \\
\hline Deterioro de la función renal & $94(2.2)$ & $108(2.6)$ & $0.86(0.65-1.13)$ & 0,28 \\
\hline
\end{tabular}

Desenlace Primario

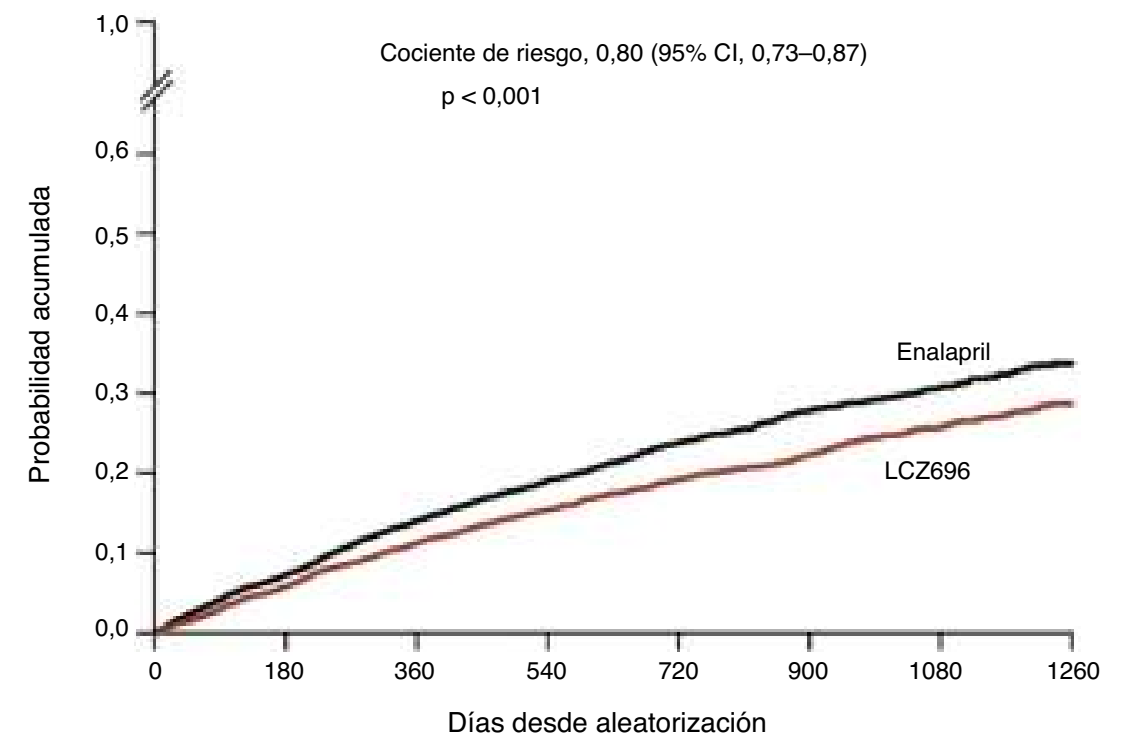

\begin{tabular}{|l|c|c|c|c|c|c|c|r|}
\hline No. En Riesgo & \multicolumn{10}{|l|}{} \\
\hline LCZ696 & 4.187 & 3.922 & 3.663 & 3.018 & 2.257 & 1.544 & 896 & 249 \\
\hline Enalapril & 4.212 & 3.883 & 3.579 & 2.922 & 2.123 & 1.488 & 853 & 236 \\
\hline
\end{tabular}

Figura 2 Curva de Kaplan Meier del estudio PARDAGIM HF.

Comparación del desenlace primario combinado: (muerte por causas cardiovasculares o primera hospitalización por insuficiencia cardiaca) entre el LCZ696 y el enalapril. Adaptado y modificado de McMurray JJ, Packer M, Desai AS, Gong J, Lefkowitz MP, Rizkala AR, et al. Angiotensin-neprilysin inhibition versus enalapril in heart failure. New England Journal of Medicine. 2014;371(11):993-1004. 


\section{Conclusión}

La inhibición de la neprilisina es una alternativa terapéutica en el manejo de la FC al prevenir la degradación de los péptidos endógenos vasoactivos y potenciar los efectos hemodinámicos de éstos. El estudio PARADIGM replantea a los IECAs como piedra angular en el manejo de la FC crónica y muy posiblemente el LCZ696 será incluido en las guías de las diferentes sociedades científicas como el primer escalón terapéutico para el manejo médico de este tipo de pacientes.

"Insanity: doing the same thing over and over again and expecting different results',. A. Einstein

\section{Responsabilidades éticas}

Protección de personas y animales. Los autores declaran que para esta investigación no se han realizado experimentos en seres humanos ni en animales.

Confidencialidad de los datos. Los autores declaran que en este artículo no aparecen datos de pacientes.

Derecho a la privacidad y consentimiento informado. Los autores declaran que en este artículo no aparecen datos de pacientes.

\section{Conflicto de intereses}

El Dr. Buitrago y la Dra. Wills han recibido honorarios por investigación de Novartis. El Dr. Buitrago es conferencista de Novartis.

\section{Bibliografía}

1. McMurray JJ, Packer M, Desai AS, Gong J, Lefkowitz MP, Rizkala AR, et al. Angiotensin-neprilysin inhibition versus enalapril in heart failure. New England Journal of Medicine. 2014;371(11):993-1004.

2. Mangiafico S, Costello-Boerrigter LC, Andersen IA, Cataliotti A, Burnett JC. Neutral endopeptidase inhibition and the natriuretic peptide system: an evolving strategy in cardiovascular therapeutics. European heart journal. 2012, ehs262.

3. Martinez-Rumayor A, Richards AM, Burnett JC, Januzzi JL Jr. Biology of the natriuretic peptides. The American journal of cardiology. 2008;101(3):S3-8.

4. Pandey KN. Biology of natriuretic peptides and their receptors. Peptides. 2005;26(6):901-32.

5. Collinson P. Natriuretic Peptides-A Review. 2005.

6. Epstein FH, Levin ER, Gardner DG, Samson WK. Natriuretic peptides. New England Journal of Medicine. 1998;339(5):321-8.

7. Potter LR, Yoder AR, Flora DR, Antos LK, Dickey DM. Natriuretic peptides: their structures, receptors, physiologic functions and therapeutic applications. cGMP: Effectors and Therapeutic Implications: Springer; 2009. p. 341-66.

8. Volpe M. Natriuretic peptides and cardio-renal disease. International journal of cardiology. 2014.

9. Sarzani R, Salvi F, Dessì-Fulgheri P, Rappelli A. Renin-angiotensin system, natriuretic peptides, obesity, metabolic syndrome, and hypertension: an integrated view in humans. Journal of hypertension. 2008;26(5):831-43.
10. Kim H-N, Januzzi JL. Natriuretic peptide testing in heart failure. Circulation. 2011;123(18):2015-9.

11. Daniels LB, Maisel AS. Natriuretic peptides. Journal of the American College of Cardiology. 2007;50(25):2357-68.

12. Tagore R, Ling LH, Yang H, Daw H-Y, Chan Y-H, Sethi SK. Natriuretic peptides in chronic kidney disease. Clinical Journal of the American Society of Nephrology. 2008;3(6):1644-51.

13. Nishikimi T, Yoshihara F, Mori Y, Kangawa K, Matsuoka H. Cardioprotective effect of adrenomedullin in heart failure. Hypertension research: official journal of the Japanese Society of Hypertension. 2003;26:S121-7.

14. Wong HK, Cheung TT, Cheung BM. Adrenomedullin and cardiovascular diseases. JRSM cardiovascular disease. 2012;1(5): 14.

15. Peacock WF. Novel biomarkers in acute heart failure: MR-proadrenomedullin. Clinical Chemistry and Laboratory Medicine (CCLM). 2014.

16. Golias C, Charalabopoulos A, Stagikas D, Charalabopoulos K, Batistatou A. The kinin system-bradykinin: biological effects and clinical implications Multiple role of the kinin systembradykinin. Hippokratia. 2007;11(3):124.

17. Costa G, Leite-Moreira A, Henriques-Coelho T. Cardiovascular effects of the angiotensin type 2 receptor. Revista Portuguesa de Cardiología (English Edition). 2014.

18. Dell'Italia LJ, Oparil S. Bradykinin in the Heart Friend Or Foe? Circulation. 1999;100(23):2305-7.

19. Knecht SE, Dunn SP, Macaulay TE. Angioedema Related to Angiotensin Inhibitors. Journal of pharmacy practice. 2014, 0897190014546101.

20. Mentz RJ, Barkis GL, Waeber B, McMurray JJ, Gheorghiade M, Ruilope LM, et al. The past, present and future of reninangiotensin aldosterone system inhibition. International Journal of Cardiology. 2013;167:1677-87.

21. Gradman AH. Evolving understanding of the renin-angiotensinaldosterone system: pathophysiology and targets for therapeutic intervention. Am Heart J. 2009;157:S1-6.

22. Givertz MM. Manipulation of the renin-angiotensin system. Circulation. 2001;104. E14-?

23. Leopold JA. Aldosterone, mineralocorticoid receptor activation, and cardiovascular remodeling. Circulation. 2011;124: e466-8.

24. Mangiafico S, Costello-Boerrigter LC, Andersen IA, Cataliotti A, Burnett JC Jr. Neutral endopeptidase inhibition and the natriuretic peptide system: an evolving strategy in cardiovascular therapeutics. European Heart Journal. 2013;34:886-93.

25. Von Lueder TG, Atar D, Krum H. Current role of neprilysin inhibitors in hypertension and heart failure. Pharmacology \& Therapeutics. 2014;144:41-9.

26. Ando S, Rahman MA, Butler GC, Senn BL, Floras JS. Comparison of candoxatril and atrial natriuretic factor in healthy men. Effects on hemodynamics, sympathetic activity, heart rate variability and endothelin. Hypertension. 1995;26 $6 \mathrm{Pt}$ 2:1160-6.

27. McDowell G, Nicholls DP. The endopeptidase inhibitor, candoxatril, and its therapeutic potential in the treatment of chronic cardiac failure in man. Expert Opin Investig Drugs. 1999;8:79-84.

28. Bevan EG, Connell JM, Doyle J, Carmichael HA, Davies DL, Lorimer AR, et al. Candoxatril, a neutral endopeptidase inhibitor: efficacy and tolerability in essential hypertension. J Hypertens. 1992;10:607-13.

29. Kostis JB, Packer M, Black HR, Schmieder R, Henry D, Levy E. Omapatrilat and enalapril in patients with hypertension: the Omapatrilat Cardiovascular Treatment vs. Enalapril (OCTAVE) trial. Am J Hypertens. 2004;17:103-11.

30. Packer M, Califf RM, Konstam MA, Krum H, McMurray JJ, Rouleau $\mathrm{JL}$, et al. Comparison of omapatrilat and enalapril in patients with chronic heart failure: the Omapatrilat Versus Enalapril 
Randomized Trial of Utility in Reducing Events (OVERTURE). Circulation. 2002;106:920-6.

31. Feng L, Karpinski PH, Sutton P, Liu Y, Hook D, Hu B, et al. LCZ696: a dual-acting sodium supramolecular complex. Tetrahedron Lett. 2012;53:275-6.

32. Gu J, Noe A, Chandra P, Al-Fayoumi S, Al-Fayoumi S, Ligueros-Saylan M, Sarangapani R, et al. Pharmacokinetics and pharmacodynamics of LCZ696, a novel dual-acting angiotensin receptor-neprilysin inhibitor (ARNi). J Clin Pharmacol. 2010;50:401-14.

33. Von Lueder TG, Sangaralingham SJ, Wang BH, Kompa AR, Atar D, Burnett JC, et al. Renin-angiotensin blockade combined with natriuretic peptide system augmentation: novel therapeutic concepts to combat heart failure. Circ Heart Fail. 2013;6:594-605.

34. Cohn JN, Tognoni G. A randomized trial of the angiotensinreceptor blocker valsartan in chronic heart failure. New England Journal of Medicine. 2001;345(23):1667-75.

35. Young JB, Dunlap ME, Pfeffer MA, Probstfield JL, Cohen-Solal A, Dietz R, et al. Mortality and morbidity reduction with candesartan in patients with chronic heart failure and left ventricular systolic dysfunction results of the CHARM low-left ventricular ejection fraction trials. Circulation. 2004;110(17): 2618-26. 